\title{
REVIEW
}

\section{Developmental origin of polycystic ovary syndrome - a hypothesis}

\author{
D H Abbott, D A Dumesic ${ }^{1}$ and S Franks ${ }^{2}$ \\ Department of Obstetrics and Gynecology and Wisconsin Regional Primate Research Centre, University of Wisconsin, Madison, Wisconsin 53715, USA \\ ${ }^{1}$ Department of Obstetrics and Gynecology, The Mayo Clinic, Rochester, Minnesota 55905, USA \\ ${ }^{2}$ Department of Reproductive Science and Medicine, Institute of Reproductive and Developmental Biology, Imperial College, University of London, \\ Hammersmith Hospital, London W12 0NN, UK \\ (Requests for offprints should be addressed to S Franks; Email: s.franks@ic.ac.uk)
}

\begin{abstract}
Polycystic ovary syndrome (PCOS) is a common but complex endocrine disorder and is a major cause of anovulation and consequent subfertility. It is also associated with a metabolic disturbance, characterized by hyperinsulinaemia and insulin resistance that carries an increased risk of type 2 diabetes in later life. Despite its prevalence little is known about its aetiology, but there is increasing evidence for an important genetic involvement. On the basis of experimental observations in the prenatally androgenized sheep and rhesus monkey, and supported by data from human studies, we propose that the clinical and biochemical features of PCOS can arise as a consequence of genetically determined hypersecretion of androgens by
\end{abstract}

the ovary during, or very likely long before, puberty. The resulting hyperandrogenism results in 'programming' of the hypothalamic-pituitary unit to favour excess LH secretion, and encourages preferential abdominal adiposity that predisposes to insulin resistance. The severity of hyperinsulinaemia and insulin resistance (which has a profound influence on the phenotype of PCOS) is further influenced by both genetic factors (such as polymorphism in the insulin gene regulatory region) and environmental factors, notably obesity. This hypothesis therefore suggests a unifying, 'linear' model to explain the aetiology of the heterogeneous phenotype.

Journal of Endocrinology (2002) 174, 1-5

\section{Introduction}

Polycystic ovary syndrome (PCOS) is the most common, yet complex, endocrine disorder affecting women in their reproductive years. Its complexity stems from the syndrome's typical heterogeneity (Table 1) and its unknown aetiology. There is increasing evidence to support a major genetic basis for PCOS, since the syndrome is strongly familial (Franks et al. 1997, Legro et al. 1998a). It is clear, however, that more than one gene (and probably several) contribute to the heterogeneous phenotype (Franks et al. 1997, Urbanek et al. 1999) and the clinical and biochemical presentation is undoubtedly influenced by additional environmental factors, such as diet and exercise (Huber-Buchholz et al. 1999). Given the complex interactions of such variables on the PCOS phenotype, a single developmental origin for the heterogeneous PCOS characteristics (Table 1) might seem unlikely. Nevertheless, results from recent experiments using animal models, together with supporting clinical evidence, lead us to propose that the development of PCOS is a linear process with an origin before adolescence (the contemporary clinical perception of age of onset of PCOS). Super- imposed on this developmental process are interacting genetic and environmental factors that may alter phenotypic expression of PCOS during adult life, particularly the susceptibility to anovulation (White et al. 1995, Franks et al. 1997, Chang et al. 2000).

\section{In utero androgen excess programmes for PCOS in non-human primates and sheep}

Adult, female rhesus monkeys exposed, in utero, to levels of testosterone equivalent to those found in fetal males show many clinical and biochemical features of PCOS. They particularly exhibit hypersecretion of luteinizing hormone (LH), abnormal insulin secretion or action and, in obese (hyperinsulinaemic) individuals, hyperandrogenic anovulation (Abbott et al. 1998, Eisner et al. 2000). These observations have been verified in recent studies of sheep, in which exposure of the pregnant ewe to large doses of testosterone causes increased LH secretion and abnormal ovarian cycles in female offspring (Padmanabhan et al. 1998, Robinson et al. 1999). Interestingly, prenatally androgenized females in both species develop enlarged ovaries with multiple, medium-sized antral follicles. 
Table 1 Important disorders of reproduction, metabolism and general health that are manifest in women with polycystic ovaries: their combination and degree of expression are highly variable between individuals, including first-degree relatives

\author{
Reproductive disorders \\ Polycystic ovaries \\ Hyperandrogenism (hirsutism, acne, androgenic alopecia) \\ Anovulation (amenorrhoea, oligomenorrhoea) \\ Hypersecretion of $\mathrm{LH}$ \\ Increased risk of early miscarriage \\ Metabolic disorders \\ Hyperinsulinaemia and insulin resistance \\ Impaired pancreatic $\beta$-cell insulin secretion and type 2 diabetes \\ Obesity (including preferential abdominal adiposity) \\ Hyperlipidaemia \\ Disorders of general health \\ Increased cardiovascular disease risk factors \\ Endometrial cancer
}

How, then, do these studies further our understanding of the aetiology of PCOS in women? They certainly suggest that abnormal $\mathrm{LH}$ and androgen secretion, menstrual cyclicity and insulin secretion and action represent exposure of the female fetus to very high levels of androgen. A similar phenomenon in PCOS seems unlikely since any maternal source of excess androgen production is unlikely to affect the human female fetus. Even pregnant women with extremely high circulating levels of testosterone (due, for example, to an ovarian thecoma) are unlikely to have a virilized female child (McLamrock \& Adashi 1992). Together, high circulating concentrations of sex hormone-binding globulin and efficient placental metabolism of androgens provide an effective buffer against excess maternal androgen reaching the fetal circulation. In other words, it is difficult to imagine that hyperandrogenism is commonly passed across the placenta from a mother with PCOS to a previously unaffected daughter, unless other circumstances exist that compromise placental function, such as placental aromatase deficiency, stress or inadequate diet.

It is more likely that a hyperandrogenic fetal ovary (Barbieri et al. 1986, Beck-Peccoz et al. 1991), hyperandrogenic adrenal cortex (Barnes et al. 1994), or both, are sources of excess prenatal androgen production. Barnes et al. (1994) noted that patients with adrenal hyperandrogenism, due to 21-hydroxylase deficiency, also showed evidence of polycystic ovaries and excess ovarian androgen production. Adrenal androgens may be used as a substrate for ovarian androgen production. Both the fetal and adult ovary are able to convert steroid precursors, including adrenal dehydroepiandrosterone sulphate, to potent androgens (and thence to oestrogens) (Payne \& Jaffe 1974, Bonser et al. 2000).

Androgens produced during differentiation are potent gene transcription factors and induce other critical transcription factors (such as $c-f o s$ ) that interact with their own receptors in many fetal tissues, permanently enhancing gene expression (including increased serine phosphorylation of the cAMP response element) (Auger et al. 2001). It is therefore feasible that fetal androgen excess in human females simultaneously reprogrammes multiple organ systems that will later manifest the heterogeneous phenotype of PCOS (Table 1). Virilization of female genitalia, as a potential phenotypic consequence of fetal androgen excess, does not occur in women with PCOS. Such virilization, however, does not reliably accompany fetal androgen excess in either humans (Barnes et al. 1994) or rhesus monkeys (Herman et al. 2000), illustrating the subtle, but permanent, effects androgen reprogramming can exert on female physiology.

\section{Evidence for a primary ovarian disorder affecting androgen production in PCOS}

Irrespective of the mode of clinical presentation or degree of menstrual cycle dysfunction, excess production of androgen is the most consistent biochemical feature of both women with PCOS (Franks 1991, Legro et al. 1998b) and prenatally androgenized female rhesus monkeys (Abbott et al. 1998). Even women or female monkeys with typical ovarian morphology and normal menstrual cyclicity have biochemical evidence of hyperandrogenism. Although the adrenal may contribute to excess testosterone circulating in women with PCOS (Azziz et al. 1998) and in prenatally androgenized female rhesus monkeys, the major source of excess androgens is the ovary (Ehrmann et al. 1995, Gilling-Smith et al. 1997, Eisner et al. 2002).

Both in vivo and in vitro studies of theca cell function show an intrinsic abnormality of ovarian steroidogenesis. The ovarian androgen response is exaggerated in women with PCOS following stimulation by exogenous human chorionic gonadotrophin (hCG) (Gilling-Smith et al. 1997) or by endogenous gonadotrophin (after treatment with exogenous gonadotrophin-releasing-hormone (GnRH) analogue) (Ehrmann et al. 1995, White et al. 1995). A pronounced ovarian androgen response is also evoked by exogenous hCG in adult female rhesus monkeys, androgenized prenatally (Eisner et al. 2002). In women with PCOS, increased thecal steroid production in response to hCG remains evident after long-term LH suppression by a GnRH analogue (Gilling-Smith et al. 1997).

Cultured human theca cells from polycystic ovaries produce 20 times more androstenedione than similar cells from normal ovaries (Gilling-Smith et al. 1994). Recently, these observations have been confirmed in long-term cultures of human theca cells, in which increased mRNA expression for many steroidogenic enzymes was evident (Wickenheisser et al. 2000). These findings reflect the increase in progesterone and 17-hydroxyprogesterone accumulation (as well as androstenedione) observed in primary theca cell cultures (Gilling-Smith et al. 1994) and suggest a global enhancement of steroidogenesis. 


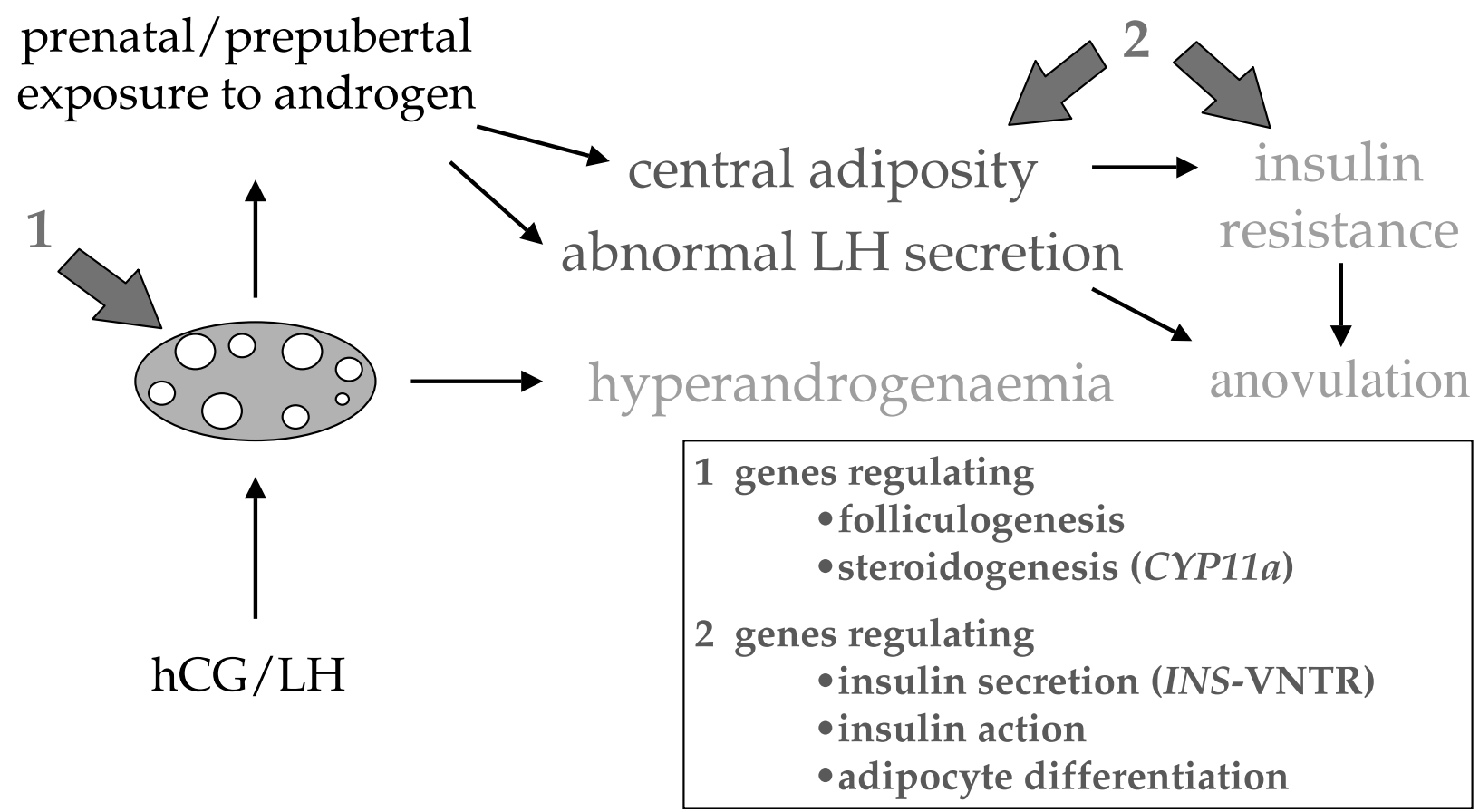

Figure 1 Diagrammatic representation of our hypothesis for the developmental origin of PCOS. During gestation, placental hCG, fetal pituitary LH and genes regulating folliculogenesis and steroidogenesis individually, or in concert, result in fetal ovarian hyperandrogenaemia leading to prenatal (and potentially prepubertal) exposure of the developing female to excess androgen. Post-pubertally, the early exposure to androgen excess (i) diminishes steroid hormone negative feedback on pituitary LH producing abnormal LH secretion and (ii) predisposes to preferential accumulation of abdominal (central) adiposity that exaggerates insulin resistance (the latter are enhanced by genes regulating adipocyte differentiation, and insulin secretion and action). The resultant hyperinsulinaemia synergistically interacts with LH hypersecretion to augment ovarian steroidogenesis and to induce premature arrest of follicle development and anovulation.

These findings in cultured human theca cells prompted consideration of genes encoding steroidogenic enzymes as candidate loci in the aetiology of PCOS. One polymorphism - a pentanucleotide repeat - was identified in the promoter region of CYP11a. Evidence has been found for association and linkage of variants at the CYP11a locus with hyperandrogenism in women with PCOS (Gharani et al. 1997). While it is unlikely to be the exclusive cause of PCOS, variation at this locus may contribute to excess androgen production, supporting the view that there is a genetically determined abnormality of ovarian function. It is possible that abnormal theca cell function is the consequence of abnormal ovarian follicular development. As yet, there is little evidence for a genetic basis for impaired follicular development in PCOS since the recent findings implicating the follistatin gene in the aetiology of the syndrome (Urbanek et al. 1999) remain unconfirmed (Urbanek et al. 2000b). Nevertheless, such studies reinforce the possibility that abnormal ovarian folliculogenesis may indeed be the key ovarian abnormality.

\section{Abnormal LH secretion is secondary to ovarian dysfunction}

In anovulatory PCOS women, the predominant reason for high serum LH concentrations (representing increased LH pulse amplitude and - in some studies pulse frequency) is abnormal negative feedback that would otherwise be provided by cyclical changes in gonadal steroids. If, for example, LH levels are monitored regularly over a period of several weeks, tonically high serum LH concentrations may fall into the normal range if a spontaneous ovulatory cycle occurs (Franks 1989, Taylor et al. 1997). Nevertheless, LH secretion remains higher than normal (although significantly lower than in anovulatory subjects) in women with polycystic ovaries and regular cycles, but who have symptoms and signs of hyperandrogenism (Franks 1989, 1991). This also is a feature of prenatally androgenized rhesus monkeys and ewes, suggesting that in utero exposure to androgen may permanently diminish hormonal negative feedback on the hypothalamicpituitary axis, thereby stimulating androgen hypersecretion. Indirect evidence for such in utero programming in humans is provided by elevated serum LH levels in women with hyperandrogenaemia from classical 21-hydroxylase deficiency, an adrenal cause of hyperandrogenism (Ehrmann et al. 1995). The mechanism for this LH hypersecretion is not entirely clear, but recent data suggest that it involves impaired negative feedback on LH secretion mediated by either oestradiol or progesterone in women with PCOS (Eagleson et al. 
2000), prenatally androgenized female rhesus monkeys (Steiner et al. 1976) and prenatally androgenized ewes (Robinson et al. 1999).

\section{The origin of insulin resistance and its relationship to the mechanism of anovulation}

Anovulatory women with PCOS are relatively hyperinsulinaemic and more insulin resistant than weightmatched control subjects (Dunaif 1997). Causes of the metabolic abnormalities in PCOS remain uncertain, but include an intrinsic abnormality of post-receptor insulin signalling (e.g. excess serine phosphorylation) and abnormal insulin secretion (Holte et al. 1995, Dunaif 1997, Eisner et al. 2002). Female rhesus monkeys exposed to androgen excess in utero also exhibit specific impairments of insulin secretion or insulin action depending on whether the androgen excess occurred during early or late gestation respectively (Eisner et al. 2000). The key question is whether these features represent a primary defect in the insulin-signalling pathway (or in the $\beta$ cell) or whether they reflect the abnormal androgen environment. In support of the former, three recent reports have implicated polymorphisms in women with PCOS for genes involved with insulin secretion and with the insulin receptor (Waterworth et al. 1997, Urbanek et al. 2000a, Tucci et al. 2001). On the other hand, Holte et al. (1995) observed that weight reduction in obese women with PCOS significantly improved insulin sensitivity, noting also that the post-diet insulin sensitivity index, after reduction of abdominal adiposity, was normalized compared with weight-matched control subjects. This finding supports the hypothesis that body fat distribution is a major determinant of insulin insensitivity in PCOS. Our hypothesis is that the endocrine environment (in particular hyperandrogenaemia) during development (and especially during prenatal life and puberty) has a profound effect on body fat distribution, with a proclivity to abdominal adiposity, thus predisposing to insulin resistance. This hypothesis is supported by data from prenatally androgenized rhesus monkeys that selectively deposit fat intra-abdominally and exhibit insulin resistance. Of course, other factors may affect insulin secretion and sensitivity, including the age of the female fetus when exposed to androgen excess (Eisner et al. 2000). Thus, evidence for abnormal insulin receptor phosphorylation or impaired $\beta$-cell function does not refute the possibility that androgen-dependent body fat distribution is a cause of insulin resistance in PCOS.

Finally, we suggest that hyperinsulinaemia contributes to the mechanism of anovulation in PCOS in women, prenatally androgenized female rhesus monkeys and ewes. Ovarian steroidogenesis is spared from the effects of insulin resistance and therefore is responsive to the high circulating concentrations of insulin. Insulin synergistically interacts with $\mathrm{LH}$ to augment steroidogenesis and to induce premature arrest of follicle development (Willis et al. 1998).

\section{Prenatal androgen excess provides the developmental origin for PCOS}

We therefore conclude that although PCOS is a complex, heterogeneous disorder, most - if not all - of the clinical and biochemical features can be explained on the basis of a developmental disorder of ovarian androgen production (Fig. 1). This fetal (and/or prepubertal; Ibanez et al. 1999) androgen excess 'programmes' the hypothalamic-pituitary control of $\mathrm{LH}$, enhances visceral fat distribution (thus predisposing to insulin resistance and anovulation) and causes the clinical manifestations of hyperandrogenism in adulthood. Other secondary genetic and environmental (particularly dietary) factors may interact with this underlying linear process to modify the final phenotype and produce the heterogeneous nature of the syndrome that afflicts so many women (Fig. 1). Such a defined, developmental aetiology for PCOS holds great promise for targeted clinical interventions that not only eliminate expression of the adult phenotype, but also improve the constellation of metabolic derangements associated with this disorder.

\section{References}

Abbott DH, Dumesic DA, Eisner JR, Colman RJ \& Kemnitz JW 1998 Insights into the development of PCOS from studies of prenatally androgenized female rhesus monkeys. Trends in Endocrinology and Metabolism 9 62-67.

Auger AP, Hexter DP \& McCarthy MM 2001 Sex difference in the phosphorylation of cAMP response element binding protein (CREB) in neonatal rat brain. Brain Research 890 110-117.

Azziz R, Rittmaster RS, Fox LM, Bradley EL Jr, Potter HD \& Boots LR 1998 Role of the ovary in the adrenal androgen excess of hyperandrogenic women. Fertility and Sterility 69 851-859.

Barbieri RL, Saltzman DH, Torday JS, Randall RW, Frigoletto FD \& Ryan KJ 1986 Elevated concentrations of the beta-subunit of human chorionic gonadotropin and testosterone in the amniotic fluid of gestations of diabetic mothers. American Journal of Obstetrics and Gynecology 154 1039-1043.

Barnes RB, Rosenfield RL, Ehrmann DA, Cara JF, Cutler L, Levitsky LL \& Rosenthal IM 1994 Ovarian hyperandrogenism as a result of congenital adrenal virilizing disorders: evidence for perinatal masculinization of neuroendocrine function in women. Journal of Clinical Endocrinology and Metabolism 79 1328-1333.

Beck-Peccoz P, Padmanabhan V, Baggiani AM, Cortelazzi D, Buscaglia M, Medri G, Marconi AM, Pardi G \& Beitins IZ 1991 Maturation of hypothalamic-pituitary-gonadal function in normal human fetuses: circulating levels of gonadotropins, their common alpha-subunit and free testosterone, and discrepancy between immunological and biological activities of circulating folliclestimulating hormone. Journal of Clinical Endocrinology and Metabolism 73 525-532.

Bonser J, Walker J, Purohit A, Reed MJ, Potter BV, Willis DS, Franks S \& Mason HD 2000 Human granulosa cells are the site of sulphatase activity and are able to utilize dehydroepiandrosterone sulphate as a precursor for oestradiol production. Journal of Endocrinology 167 465-471. 
Chang PL, Lindheim SR, Lowre C, Ferin M, Gonzalez F, Berglund L, Carmina E, Sauer MV \& Lobo RA 2000 Normal ovulatory women with polycystic ovaries have hyperandrogenic pituitaryovarian responses to gonadotropin-releasing hormone-agonist testing. Journal of Clinical Endocrinology and Metabolism 85 995-1000.

Dunaif A 1997 Insulin resistance and the polycystic ovarian syndrome: mechanism and implications for pathogenesis. Endocrine Reviews $\mathbf{1 8}$ 774-800.

Eagleson CA, Gingrich MB, Pastor CL, Arora TK, Burt CM, Evans WS \& Marshall JC 2000 Polycystic ovary syndrome: evidence that flutamide restores sensitivity of the gonadotropin-releasing hormone pulse generator to inhibition by estradiol and progesterone. Journal of Clinical Endocrinology and Metabolism 85 4047-4052.

Ehrmann DA, Barnes RB \& Rosenfield RL 1995 Polycystic ovary syndrome as a form of functional ovarian hyperandrogenism due to dysregulation of androgen secretion. Endocrine Reviews 16 322-353.

Eisner JR, Dumesic DA, Kemnitz JW \& Abbott DH 2000 Timing of prenatal androgen excess determines differential impairment in insulin secrection and action in adult female rhesus monkeys. Journal of Clinical Endocrinology and Metabolism 85 1206-1210.

Eisner JR, Barnett MA, Dumesic DA \& Abbott DH 2002 Ovarian hyperandrogenism in adult female rhesus monkeys exposed to prenatal androgen excess. Fertility and Sterility 77 167-172.

Franks S 1989 Polycystic ovary syndrome: a changing perspective (review). Clinical Endocrinology 31 87-120.

Franks S 1991 The ubiquitous polycystic ovary. Journal of Endocrinology 129 317-319.

Franks S, Gharani N, Waterworth D, Batty S, White D, Williamson R \& McCarthy M 1997 The genetic basis of polycystic ovary syndrome. Human Reproduction 12 2641-2648.

Gharani, N, Gharani N, Waterworth DM, Batty S, White D, Gilling-Smith C, Conway GS, McCarthy M, Franks S \& Williamson R 1997 Association of the steroid synthesis gene CYP11a with polycystic ovary syndrome and hyperandrogenism. Human Molecular Genetics 6 397-402.

Gilling-Smith C, Willis DS, Beard RW \& Franks S 1994 Hypersecretion of androstenedione by isolated theca cells from polycystic ovaries. Journal of Clinical Endocrinology and Metabolism 79 $1158-1165$

Gilling-Smith C, Story H, Rogers V \& Franks S 1997 Evidence for a primary abnormality of thecal cell steroidogenesis in the polycystic ovary syndrome. Clinical Endocrinology 47 93-99.

Herman RA, Jones B, Mann DR \& Wallen K 2000 Timing of prenatal androgen exposure: anatomical and endocrine effects on juvenile male and female rhesus monkeys. Hormones and Behavior $\mathbf{3 8}$ $52-66$.

Holte J, Bergh T, Berne C, Wide L \& Lithell H 1995 Restored insulin sensitivity but persistently increased early insulin secretion after weight loss in obese women with polycystic ovary syndrome. Journal of Clinical Endocrinology and Metabolism 80 2586-2593.

Huber-Buchholz MM, Carey DG \& Norman RJ 1999 Restoration of reproductive potential by lifestyle modification in obese polycystic ovary syndrome: role of insulin sensitivity and luteinizing hormone. Journal of Clinical Endocrinology and Metabolism 84 1470-1474.

Ibanez L, de Zegher F \& Potau N 1999 Anovulation after precocious pubarche: early markers and time course in adolescence. Journal of Clinical Endocrinology and Metabolism 84 2691-2695.

Legro RS, Spielman R, Urbanek M, Driscoll D, Strauss JF \& Dunaif A 1998 a Phenotype and genotype in polycystic ovary syndrome. Recent Progress in Hormone Research 53 217-256.

Legro RS, Driscoll D, Strauss JF III, Fox J \& Dunaif A 1998 b Evidence for a genetic basis for hyperandrogenemia in polycystic ovary syndrome. PNAS 95 14956-14960.
McClamrock HD \& Adashi EY 1992 Gestational hyperandrogenism. Fertility and Sterility $\mathbf{5 7}$ 257-274.

Padmanabhan V, Evans N, Taylor JA \& Robinson JE 1998 Prenatal exposure to androgens leads to the development of cystic ovaries in the sheep. Biology of Reproduction 56 (Suppl 1) 194.

Payne AH \& Jaffe RB 1974 Androgen formation from pregnenolone sulfate by the human fetal ovary. Journal of Clinical Endocrinology and Metabolism 39 300-304.

Robinson JE, Forsdike RA \& Taylor JA 1999 In utero exposure of female lambs to testosterone reduces the sensitivity of the gonadotropin-releasing hormone neuronal network to inhibition by progesterone. Endocrinology 140 5797-5805.

Steiner RA, Clifton DK, Spies HG \& Resko JA 1976 Sexual differentiation and feedback control of luteinizing hormone secretion in the rhesus monkey. Biology of Reproduction 15 206-212.

Taylor AE, McCourt B, Martin KA, Anderson EJ, Adams JM, Schoenfield D \& Hall JE 1997 Determinants of abnormal gonadotropin secretion in clinically defined women with polycystic ovary syndrome. Journal of Clinical Endocrinology and Metabolism 82 2248-2256.

Tucci S, Futterweit W, Concepcion ES, Greenberg DA, Villanueva R, Davies TF \& Tomer Y 2001 Evidence for association of polycystic ovary syndrome in Caucasian women with a marker at the insulin receptor gene locus. Journal of Clinical Endocrinology and Metabolism 86 446-449.

Urbanek M, Legro RS, Driscoll DA, Azziz R, Ehrmann D, Norman RJ, Strauss JF III, Spielman RS \& Dunaif A 1999 Thirty-seven candidate genes for polycystic ovary syndrome: strongest evidence for linkage is with follistatin. PNAS 96 8573-8578.

Urbanek M, Legro RS, Driscoll D, Strauss JF, Dunaif A \& Spielman RS 2000a Searching for the polycystic ovary syndrome genes. Journal of Pediatric Endocrinology 13 (Suppl 5) 1311-1313.

Urbanek M, Wu X, Vicekery KR, Kao LC, Christenson LK, Schneyer A, Legro RS, Driscoll DA, Strauss JF, Dunaif A \& Spielman RS $2000 b$ Allelic variants of the follistatin gene in polycystic ovary syndrome. Journal of Clinical Endocrinology and Metabolism 85 4455-4461.

Waterworth DM, Bennett ST, Gharani N, McCarthy M, Hague S, Batty S, Conway GS, White DW, Todd JA, Franks S \& Williamson R 1997 Linkage and association of insulin gene VNTR regulatory polymorphism with polycystic ovary syndrome. Lancet 349 986-990.

White DW, Leigh A, Wilson C, Donaldson A \& Franks S 1995 Gonadotrophin and gonadal steroid response to a single dose of a long-acting agonist of gonadotrophin-releasing hormone in ovulatory and anovulatory women with polycystic ovary syndrome. Clinical Endocrinology 42 475-481.

Wickenheisser JK, Quinn PG, Nelson VL, Legro RS, Strauss JF \& McAllister JM 2000 Differential activity of the cytochrome P450 17 alpha-hydroxylase and steroidogenic acute regulatory protein gene promoters in normal and polycystic ovary syndrome theca cells. Journal of Clinical Endocrinology and Metabolism 85 2304-2311.

Willis DS, Willis D, Watson H, Mason D, Galea R, Brincat M \& Franks S 1998 Premature response to luteinizing hormone of granulosa cells from anovulatory women with polycystic ovary syndrome: relevance to mechanism of anovulation. Journal of Clinical Endocrinology and Metabolism 83 3984-3991.

Received 25 February 2002 Accepted 25 April 2002 